\title{
Hérnia perineal associada à colagenopatia em uma cadela
}

\author{
Perineal hernia associated with collagenopathy in a bitch
}

\section{Liliana Borges de Menezes ${ }^{1}$ Aline de Moraes Faria ${ }^{2}$, Neusa Margarida Paulo ${ }^{3}$, Luiz Fernando Froes Fleury ${ }^{4} \&$ Marcelo Seixo de Brito e Silva ${ }^{5}$}

\begin{abstract}
RESUMO
A hérnia perineal acomete mais freqüentemente cães machos de meia idade e idosos, não castrados, podendo ser uni ou bilateral. A apresentação desta doença na fêmea pode ser sugestiva de alguma alteração estrutural no colágeno que leva às alterações da matriz extracelular. Sendo assim, o objetivo deste trabalho foi descrever um caso de hérnia perineal associada à colagenopatia em uma cadela. Foi examinada uma cadela Pinscher de 3 anos de idade, portadora de hérnia perineal bilateral. Foi observado hiperextensibilidade da pele. Este animal foi submetido á reparação da hérnia onde havia laceração da pele durante a dermorrafia. Foi realizada biópsia e coloração com HE e as alterações observadas foram diminuição do número de fibras colágenas na derme, que apresentavam aparente desordem na sua estrutura, notando-se raros feixes de fibras com acentuada fragmentação. Foi possível concluir que os achados clínicos e alterações histopatológicas são compatíveis com astenia cutânea na cadela.
\end{abstract}

Descritores: astenia, cão, colágeno, síndrome de Ehlers-Danlos.

\section{ABSTRACT}

Majority of cases the perineal hernia occur in intact male dogs that are middle-aged, sexually intact, and it may be unilateral or bilateral. That presentation of this illness in the bicth can be suggestive of some structural alteration in the collagen that leads to the alterations of the extracellular matrix. The purpose of this paper was to describe a case of perineal hernia associated to the collagenopathy in a bicth. An 3-years-old bitch was evaluated with perineal hernia bilateral. Hyperextensibility of the skin was observed. The perineal hernia was surgically repaired and it was observed laceration of the skin during the suture. It was carried through biopsy and HE staining. Histopathological examinations revealed alterations at the distribution and conformation of collagen fibers. There was rarefaction of connective tissue. Collagen fibers were shorten and frequently fragmented. It was possible to conclude that the clinical findings and histopathologics alterations are compatible with cutaneous asthenia in this dog.

Key words: asthenia, dog, collagen, Ehlers-Danlos Syndrome. 


\section{INTRODUÇÃO}

A hérnia perineal resulta do enfraquecimento e separação dos músculos e fáscias que formam o diafragma pélvico, promovendo deslocamento caudal de órgãos abdominais ou pélvicos no períneo. Acomete mais freqüentemente cães machos de meia idade e idosos [3]. Nos animais, como eqüinos, ovinos, bovinos, suínos, caninos e felinos, as doenças do tecido conjuntivo que se assemelham à síndrome de Ehlers-Danlos do ser humano, compreendem um grupo de doenças hereditárias raras do tecido conjuntivo que promovem hiperextensibilidade cutânea e lacerações. As alterações histológicas associadas a esta doença correspondem ao adelgaçamento da derme com irregularidades no tamanho, forma e afinidade das fibras colágenas pelos corantes. As fibras colágenas podem aparecem com focos de degeneração [2]. O presente relato visa descrever um caso de hérnia perineal associada à colagenopatia em uma cadela.

\section{RELATO DE CASO}

Foi examinada uma cadela Pinscher de 3 anos de idade, portadora de hérnia perineal bilateral. Ao exame clínico foi notado hiperextensibilidade cutânea e o proprietário relatou que freqüentemente o animal apresentava ferimentos na pele. Durante a hernioplastia colheu-se um fragmento de pele que foi processado de acordo com o método convencional de histologia e corado com hematoxilina e eosina (HE) e Mallory.

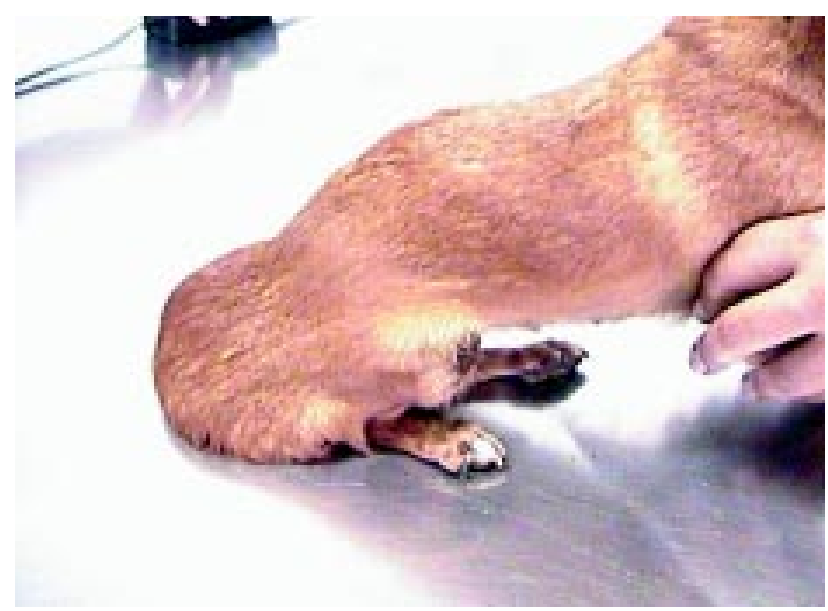

Figura 1. Animal apresentando hiperextensibilidade cutânea na região posterior.

\section{DISCUSSÃO}

As colagenopatias podem provocar freqüentes ferimentos no corpo [2]. Ao exame clinico o animal apresentava abaulamento bilateral no períneo e hiperextensibilidade de pele, formando um grande saco nesta região (Figura 1). Ao ser operado para hernioplastia, verificou-se estrangulamento de jejuno no anel herniário, procedendo-se enterectomia com enteroanastomose. Fez-se a implantação bilateral de tela de polipropileno para oclusão dos anéis herniários. Removido o excesso de pele notou-se que durante a síntese a pele sofria desgarros nos pontos de introdução da agulha e apresentava-se fina e frágil, não suportando as suturas, o que também foi salientado por outros autores [4]. $\mathrm{O}$ animal veio a óbito duas horas após o procedimento cirúrgico. De acordo com alguns relatos [3] as hérnias perineais são freqüentes no macho da espécie canina, mas a apresentação desta doença na fêmea pode ser sugestiva de alguma alteração estrutural no colágeno levando às alterações da matriz extracelular. A hiperextensibilidade cutânea é um indicador favorável ao diagnóstico da astenia cutânea já que as alterações histológicas do colágeno podem estar presentes em outros processos de degradação desta proteína [1].

À microscopia de luz observou-se edema, hiperemia, infiltrado inflamatório moderado e difuso no qual foi possível constatar diminuição do número de fibras colágenas na derme, que apresentavam aparente desordem na sua estrutura notando-se raros fei-

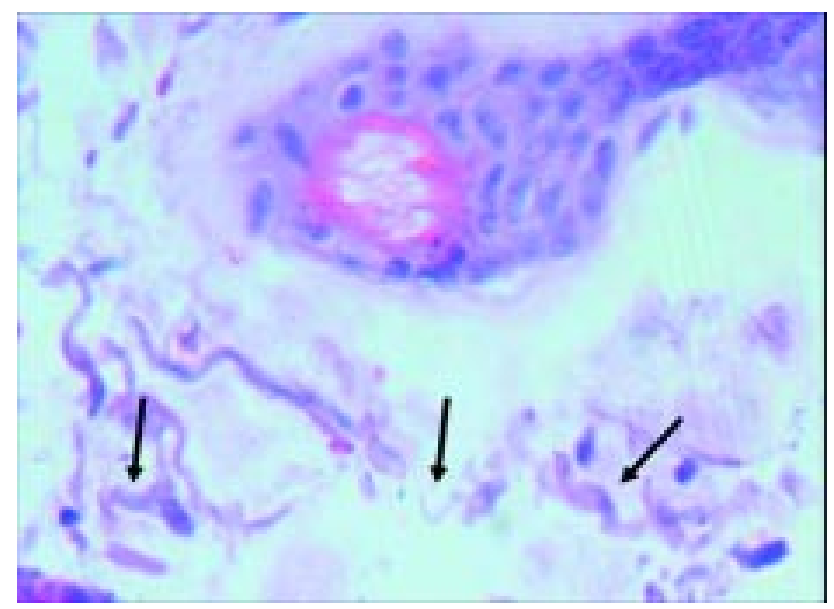

Figura 2. Fotomicrografia cutânea evidenciando decréscimo do número de fibras colágenas na derme, que apresentavam aspecto fibrilar notando-se raros feixes de fibras com acentuada fragmentação (seta). HE 400x. 
xes de fibras com acentuada fragmentação (Figura 2) também observado por outros autores [2,6], cujos achados clínicos, histológicos e ultraestruturais em dois cães com alterações se assemelhavam à síndrome Ehlers-Danlos. Eles afirmaram também, que os defeitos primários nas colagenopatias em animais ainda permanecem desconhecidos e que análises estruturais das fibras colágenas juntamente com os achados clí- nicos podem auxiliar melhor na classificação destas desordens [2]. No entanto, observaram que nem todos os animais com astenia cutânea apresentam alterações suficientes para serem detectadas por exame histopatológico de rotina sendo importante observar os achados clínicos [5]. Fundamentado nos achados clínicos é possível afirmar que as alterações histopatológicas são compatíveis com astenia cutânea na cadela.

\section{REFERÊNCIAS}

1 Fernandez C.J., Scott D.W., Erb H.N. \& Minor R.R. 1998. Staining abnormalities of dermal collagen in cats with cutaneous asthenia or acquired skin fragility as demonstrated with Masson's trichrome stain. Veterinary Dermatology. 9: 49-54.

2 Paciello O., Lamagna F., Lamagna B. \& Papparella S. 2003. Ehlers-danlos-like syndrome in 2 dogs: clinical, histologic, and ultrastructural findings. Veterinary Clinical Pathology. 32: 13-18.

3 Rosch R., Junge K., Lynen P., klinge U. \& Schumpelick V. 2003. Hernia - A Collagen Disease? European Surgery - Acta Chirurgica Austriaca. 35: 11-15.

4 Rubin E., Gorstein F., Rubin R., Schwarting R. \& Strayer D. 2006. Rubin patologia: bases clinicopatológicas da medicina. 7.ed. Rio de Janeiro: Guanabara,1624p.

5 Sequeira J.L., Rocha N.S., Bandarra E.P., Figueiredo L.M.A. \& Eugenio F.R. 1999. Collagen Dysplasia (Cutaneous Asthenia) in a Cat. Veterinary Pathology. 36: 603-606.

6 Szczepanik M., Go³ỹ̃ski M., Wilkoek P., Popiel J., CEmiech A., Pomorska D. \& Nowakowsk H. 2006. Ehlers-danlos syndrome (cutaneous asthenia) - a report of three cases in cats. Bulletin of the Veterinary Institute in Pulawy. 50: 609-612. 